\title{
Sediminibacter furfurosus gen. nov., sp. nov. and Gilvibacter sediminis gen. nov., sp. nov., novel members of the family Flavobacteriaceae
}

\author{
Shams Tabrez Khan, Yasuyoshi Nakagawa and Shigeaki Harayama \\ Biological Resource Center (NBRC), National Institute of Technology and Evaluation (NITE), \\ 2-5-8 Kazusa-kamatari, Kisarazu, Chiba 292-0818, Japan
}

Correspondence

Shams Tabrez Khan

shams-tabrez-khan@nite.go.jp

\begin{abstract}
Two Gram-negative, chemoheterotrophic, non-motile strains, Mok-1-36 ${ }^{\top}$ and MAOS- $86^{\top}$, were isolated from marine-sediment samples collected from the coasts of Okinawa island and the city of Odawara in Japan, respectively. Phylogenetic studies based on 16S rRNA gene sequences indicated that Mok-1-36 ${ }^{\top}$ and MAOS $-86^{\top}$ were members of the family Flavobacteriaceae, clustering with members of the genera Ulvibacter and Vitellibacter, respectively. Strains Mok-1-36 ${ }^{\top}$ and MAOS $-86^{\top}$ shared pairwise $16 \mathrm{~S}$ rRNA gene sequence similarities of 93.5 and $89.1 \%$ with the type strains of Ulvibacter litoralis and Vitellibacter vladivostokensis, respectively. Phylogenetic distinctiveness and phenotypic differences from their phylogenetic neighbours indicated that these strains represent two novel species and genera within the family Flavobacteriaceae, for which the names Sediminibacter furfurosus gen. nov., sp. nov. (MAOS-86 ${ }^{\top}$ ) and Gilvibacter sediminis gen. nov., sp. nov. (Mok-1-36 ${ }^{\top}$ ) are proposed. The type strain of Sediminibacter furfurosus is MAOS $-86^{\top}\left(=\right.$ NBRC $101622^{\top}=$ CIP $\left.109285^{\top}\right)$ and the type strain of Gilvibacter sediminis is Mok-1-36 ${ }^{\top}\left(=\right.$ NBRC $101626^{\top}=$ CIP $\left.109286^{\top}\right)$.
\end{abstract}

Since the description of the family Flavobacteriaceae (Reichenbach, 1992; Bernardet et al., 2002), a number of novel genera have been included. This family is one of the major branches of the phylum Bacteroidetes, and includes many marine species. They are chemoorganotrophs and play an important role in the carbon cycles of marine ecosystems (Abell \& Bowman, 2005).

This paper describes the characterization of two strains, Mok- $1-36^{\mathrm{T}}$ and MAOS- $86^{\mathrm{T}}$, isolated from marine-sediment samples collected from the coasts of Okinawa island and the city of Odawara, Japan, respectively. An analysis of their physiological, chemotaxonomic and morphological properties indicated that these two strains represent two novel species and genera within the family Flavobacteriaceae.

Marine-sediment samples were serially diluted with sterile artificial seawater (Naigai Chemicals) and spread on halfstrength marine agar (HSMA) plates [18.7 g marine broth 2216 (Difco) dissolved in 11 artificial seawater and solidified with $1.6 \%$ agar]. The plates were incubated at $30{ }^{\circ} \mathrm{C}$ for 5 days. Single colonies from the plates were picked and purified on plates containing the same medium at the same temperature. For routine cultivation and for most investigations, the same agar or the corresponding broth (HSMB)

The GenBank/EMBL/DDBJ accession numbers for the 16S rRNA gene sequences of strain MAOS- $86^{\top}$ and strain Mok-1-36 ${ }^{\top}$ are respectively AB255369 and AB255368. was used at the same incubation temperature. Purified strains were stored at $-80{ }^{\circ} \mathrm{C}$ in artificial seawater supplemented with $20 \%$ (v/v) glycerol.

Template DNA for 16S rRNA gene analysis was prepared by using Prepman Ultra (Applied Biosystems). PCR-mediated amplification of $16 \mathrm{~S}$ rRNA genes was carried out with primers 27f and 1492r, as described by Hiraishi et al. (1994). Amplicons were directly sequenced using the BigDye Terminator version 3.1 cycle sequencing kit and analysed on an ABI PRISM 3100 Genetic Analyzer (Applied Biosystems). Sequences were edited and assembled using the ATGC program (Genetyx). The almost-complete 16S rRNA gene sequences thus obtained were compared with those in the DDBJ database by means of BLASTN searches (Altschul et al., 1990). Alignment with related sequences was performed using the CLUSTAL X software package (Thompson et al., 1997). Phylogenetic trees were then constructed using the neighbour-joining (Saitou \& Nei, 1987) and maximum-parsimony (Swofford, 2000) methods; tree topologies were evaluated and compared using the bootstrap resampling method of Felsenstein (1985), with 1000 replicates. 16S rRNA gene sequence analysis indicated that both strains were members of the family Flavobacteriaceae. The results of BLASTN searches against sequences in DDBJ showed Gelidibacter algens $\mathrm{IC}_{147^{\mathrm{T}}}$ (GenBank accession no. AF001367) and Psychroserpens sp. 18III/A01/061 (AY576714) to be the closest relatives of MAOS- $86^{\mathrm{T}}$ and Mok-1-36 ${ }^{\mathrm{T}}$, respectively showing $16 \mathrm{~S}$ rRNA gene sequence 
similarity levels of 92 and $93 \%$. In the neighbour-joining tree, however, strain Mok-1-36 ${ }^{\mathrm{T}}$ formed a monophyletic clade with Ulvibacter litoralis KMM $3912^{\mathrm{T}}$ (93.5\% identity) and strain MAOS- $86^{\mathrm{T}}$ formed a monophyletic clade with Vitellibacter vladivostokensis KMM $3516^{\mathrm{T}}$ (89.1\% identity) (Fig. 1); both results were supported by high bootstrap values. The maximum-parsimony tree produced a very similar topology (data not shown).

Three-day-old colonies of Mok-1-36 ${ }^{\mathrm{T}}$ on HSMA were yellow and irregular. While the colonies of MAOS $-86^{\mathrm{T}}$ appeared circular and colourless for the first 3-5 days incubation, confluent growth turned brownish after 5-6 days. The cell morphology of 3- to 5-day-old HSMA cultures was observed under an Olympus light microscope (CX41LF) without staining. The cells of both strains were rod-shaped and 0.5-0.7 $\mu \mathrm{m}$ wide. The cell length for Mok$1-36^{\mathrm{T}}$ was $3.0-5.0 \mu \mathrm{m}$ and that for MAOS- $86^{\mathrm{T}}$ was $1.0-2.5 \mu \mathrm{m}$. The hanging drop method of Perry (1973) (using a $1000 \times$ oil-immersion objective) was used to check for the presence of gliding motility; neither strain showed gliding motility. The presence of flexirubin-type pigments was assessed using the bathochromic shift test with $20 \%$ (w/v) KOH, as described by Fautz \& Reichenbach (1980). Flexirubin-type pigments were absent from both strains. To detect carotenoid-type pigments, the absorption spectra $(260-700 \mathrm{~nm})$ of acetone extracts of the cells were measured using a Shimadzu UV-visible spectrophotometer (UV-1650

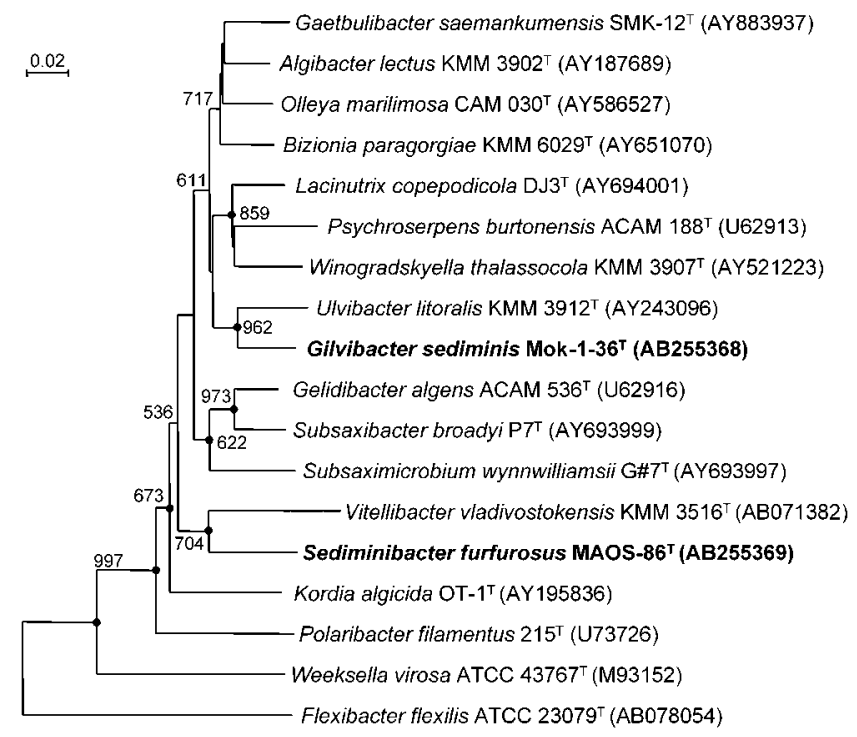

Fig. 1. Neighbour-joining phylogenetic tree, based on the analysis of almost-complete 16S rRNA gene sequences, showing the positions of strains Mok-1-36 ${ }^{\top}$ and MAOS $-86^{\top}$ in the family Flavobacteriaceae. Flexibacter flexilis ATCC $23079^{\top}$ was used as an outgroup. Numbers at nodes show bootstrap values (when more than 500) calculated from 1000 resampling units. Filled circles indicate nodes that were also recovered in the maximum-parsimony tree. Bar, $0.02 K_{\text {nuc. }}$.
PC). Carotenoid pigments were detected only in strain Mok-1 $-36^{\mathrm{T}}$. Catalase activity was revealed by the production of oxygen bubbles when cells harvested from colonies grown on HSMA plates were mixed with a drop of $3 \%(\mathrm{v} / \mathrm{v})$ hydrogen peroxide on a glass slide. Oxidase activity was assessed using a cytochrome oxidase test strip (Nissui Pharmaceuticals) on which cells from 2- to 3-day-old cultures suspended in distilled water were spotted. Both strains were positive for catalase and oxidase.

The ability to grow at different temperatures was examined on HSMA plates at $4,10,15,20,25,30,37,40$ and $42^{\circ} \mathrm{C}$. Tolerance of high $\mathrm{NaCl}$ concentrations was assessed in $\mathrm{HSMB}$ with final $\mathrm{NaCl}$ concentrations adjusted to 4, 5, 6, 7, 8,9 and $10 \%(w / v)$. Growth in one-fifth-strength LuriaBertani medium [12 g Bacto tryptone (Difco) and $1 \mathrm{~g}$ Bacto yeast extract (Difco) per litre distilled water] supplemented

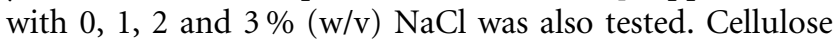
degradation was tested by placing cellulose-paper strips (Whatman No. 1 filter paper) in cultures in one-fifthstrength Luria-Bertani medium made up in artificial seawater (LBM medium). CM-cellulose degradation was tested by inoculating cells deeply into one-fifth-strength LBM medium solidified with $3 \%$ (w/v) CM-cellulose (high viscosity; Sigma). Degradation of agar and carrageenan (Type I; Sigma) was assessed, in each case, on plates of HSMB solidified with $1.5 \%$ (w/v) of the polymer. Degradation of starch, casein, chitin, DNA and gelatin was tested according to the protocol of Cowan \& Steel (1993). Other biochemical tests (reduction of nitrate and nitrite, production of indole from tryptophan, production of acid from glucose, presence of urease, $\beta$-galactosidase and $\beta$-glucosidase) were carried out using API 20NE strips (bioMérieux) according to the manufacturer's instructions, except that cultures were suspended in artificial seawater. Biolog GN2 MicroPlates (Biolog) were used to test for the utilization of 95 different carbon sources; the plates were inoculated as suggested by Rüger \& Krambeck (1994). The results from the API 20NE strips and the Biolog GN2 MicroPlates were recorded after incubation at $30^{\circ} \mathrm{C}$ for $12-36 \mathrm{~h}$. Additionally, utilization of several carbon sources (peptone, sucrose, maltose, raffinose, D-mannose, D-arabinose, D-galactose, L-rhamnose, L-aspartic acid, pyruvic acid, L-glutamic acid, meso-erythritol, adonitol, glycerol and xylitol) was tested using the basal medium described by Suzuki et al. (2001). The morphological and physiological characteristics of the two novel strains are given in the genus and species descriptions and in Table 1. Strains Mok-1-36 ${ }^{\mathrm{T}}$ and MAOS$86^{\mathrm{T}}$ were distinguishable from their phylogenetic neighbours on the basis of a number of phenotypic characteristics (Table 1).

Genomic DNA was prepared by using the method of Minamisawa (1990), and the DNA G $+C$ contents of Mok- $1-36^{\mathrm{T}}$ and MAOS- $86^{\mathrm{T}}$ were determined using the HPLC method of Mesbah et al. (1989); G + C contents of 43 and $39 \mathrm{~mol} \%$, respectively, were found. The method of Nakagawa \& Yamasato (1993) was used to extract and 
Table 1. Differentiating characteristics for strains Mok-1$36^{\top}$ and MAOS- $86^{\top}$

Strains: 1, Mok-1-36 ${ }^{\mathrm{T}}$; 2, U. litoralis $\mathrm{KMM} 3912^{\mathrm{T}}$ (data from Nedashkovskaya et al., 2004); 3, MAOS- $86^{\mathrm{T}} ; 4$, V. vladivostokensis KMM $3516^{\mathrm{T}}$ (Nedashkovskaya et al., 2003).

\begin{tabular}{|c|c|c|c|c|}
\hline Characteristic & 1 & 2 & 3 & 4 \\
\hline Gliding motility & - & + & - & - \\
\hline Pigmentation & Yellow & Yellow & Light brown & $\begin{array}{l}\text { Yellow- } \\
\text { orange }\end{array}$ \\
\hline $\begin{array}{l}\text { Flexirubin-type } \\
\text { pigments }\end{array}$ & - & + & - & + \\
\hline \multicolumn{5}{|l|}{ Growth at: } \\
\hline $37^{\circ} \mathrm{C}$ & + & - & + & + \\
\hline $42^{\circ} \mathrm{C}$ & - & - & - & + \\
\hline \multicolumn{5}{|l|}{ Hydrolysis of: } \\
\hline Starch & - & - & + & - \\
\hline DNA & + & - & + & + \\
\hline CM-cellulose & + & - & - & - \\
\hline $\begin{array}{l}\text { DNA G }+ \text { C content } \\
(\mathrm{mol} \%)\end{array}$ & 43 & $36-38$ & 39 & 41 \\
\hline
\end{tabular}

analyse the respiratory quinones from freeze-dried cells. Menaquinone- 6 was detected as the sole quinone in both strains. For fatty acid analysis, cells of strains MAOS- $86^{\mathrm{T}}$ and Mok-1-36 ${ }^{\mathrm{T}}$ were grown under the same conditions as their respective phylogenetic neighbours, Vitellibacter vladivostokensis and Ulvibacter litoralis, had been grown under for their original descriptions, i.e. at $28{ }^{\circ} \mathrm{C}$ for $72 \mathrm{~h}$ on medium A (Nedashkovskaya et al., 2003) and on marine agar 2216 (Nedashkovskaya et al., 2004), respectively. As the growth temperature and duration of incubation for $U$. litoralis were not specified in the latter study, strain Mok- $1-36^{\mathrm{T}}$ was also grown at $28^{\circ} \mathrm{C}$ for $72 \mathrm{~h}$. The standard protocol of the Microbial Identification system (MIDI; Microbial ID) was used. The major fatty acids of strain Mok- $1-36^{\mathrm{T}}$ were iso$15: 0$, iso- $15: 1$, iso- $16: 03-\mathrm{OH}$ and iso- $17: 03-\mathrm{OH}$, very similar to those determined (using the MIDI system) for $U$. litoralis (Nedashkovskaya et al., 2004). The predominant fatty acids of MAOS- $86^{\mathrm{T}}$ were iso- $15: 0$, iso- $15: 1$, iso- $17: 0$ $3-\mathrm{OH}$ and summed feature 3 ( $16: 1 \omega 7 c$ and/or iso-15:0 2$\mathrm{OH})$. This fatty acid profile was notably different from that determined for $V$. vladivostokensis using a different chromatography procedure (Nedashkovskaya et al., 2003). The detailed fatty acid profiles for the four taxa are given in Table 2.

Hence, the novel taxonomic status of the two isolates is supported by their unique phenotypic traits (Tables 1 and 2), and it is concluded that strains Mok- $1-36^{\mathrm{T}}$ and MAOS- $86^{\mathrm{T}}$ represent novel species of two novel genera within the family Flavobacteriaceae. The names Sediminibacter furfurosus gen. nov., sp. nov. and Gilvibacter sediminis gen. nov., sp. nov. are proposed for strains MAOS- $86^{\mathrm{T}}$ and Mok-1-36 ${ }^{\mathrm{T}}$, respectively.
Table 2. Fatty acid compositions (\%) of strains Mok-1-36 and MAOS-86 $6^{\top}$, U. litoralis KMM $3912^{\top}$ and V. vladivostokensis KMM $3516^{\top}$

Strains: 1, Mok-1-36 $; 2$, U. litoralis $\mathrm{KMM} 3912^{\mathrm{T}}$ (data from Nedashkovskaya et al., 2004); 3, MAOS-86 ${ }^{\mathrm{T}}$; $4, V$. vladivostokensis KMM $3516^{\mathrm{T}}$ (Nedashkovskaya et al., 2003). The fatty acid compositions of Mok-1-36, U. litoralis KMM $3912^{\mathrm{T}}$ and MAOS- $86^{\mathrm{T}}$ were determined using the MIDI system, whereas that of V. vladivostokensis $\mathrm{KMM} 3516^{\mathrm{T}}$ was determined using another GLC method (Nedashkovskaya et al., 2003). tr, Trace $(<1 \%$ of the total fatty acid content); NR, not reported; ND, not detected.

\begin{tabular}{|c|c|c|c|c|}
\hline Fatty acid & 1 & 2 & 3 & 4 \\
\hline iso- $14: 0$ & 1 & 2 & $\operatorname{tr}$ & NR \\
\hline iso- $15: 0$ & 19 & 21 & 39 & 68 \\
\hline anteiso- $15: 0$ & 1 & 2 & 2 & 8 \\
\hline iso- $15: 1$ & 15 & 13 & 25 & 2 \\
\hline $15: 0$ & $\mathrm{ND}$ & 4 & ND & 4 \\
\hline $15: 1 \omega 6 c$ & $\mathrm{ND}$ & 1 & $\operatorname{tr}$ & NR \\
\hline $16: 0$ & 2 & NR & 2 & 2 \\
\hline iso- $16: 0$ & 7 & 3 & $\operatorname{tr}$ & 3 \\
\hline iso- $16: 1$ & 4 & 4 & $\operatorname{tr}$ & $\operatorname{tr}$ \\
\hline iso- $17: 0$ & $\mathrm{ND}$ & NR & ND & 3 \\
\hline iso- $17: 1$ & $\mathrm{ND}$ & NR & ND & 4 \\
\hline iso- $17: 1 \omega 9 c$ & $\mathrm{ND}$ & 4 & 3 & NR \\
\hline $17: 1 \omega 6 c$ & $\operatorname{tr}$ & 2 & $\operatorname{tr}$ & NR \\
\hline $15: 02-\mathrm{OH}$ & 1 & 1 & $\operatorname{tr}$ & NR \\
\hline iso- $15: 03-\mathrm{OH}$ & 5 & 3 & 6 & 2 \\
\hline iso-16:0 $3-\mathrm{OH}$ & 9 & 9 & 1 & NR \\
\hline iso-17:0 $3-\mathrm{OH}$ & 16 & 17 & 9 & $\operatorname{tr}$ \\
\hline $17: 02-\mathrm{OH}$ & $\operatorname{tr}$ & 2 & $\operatorname{tr}$ & NR \\
\hline Summed feature $3^{*}$ & 7 & 6 & 9 & NR \\
\hline
\end{tabular}

${ }^{*}$ Summed feature 3 contains $16: 1 \omega 7 c$ and/or iso-15:0 2-OH.

\section{Description of Sediminibacter gen. nov.}

Sediminibacter (Se.di.mi.ni.bac'ter. L. n. sedimen -inis sediment; N.L. masc. bacter rod; N.L. masc. n. Sediminibacter a rod from sediment).

Cells are non-motile, Gram-negative, aerobic, rod-shaped and lack carotenoid and flexirubin-type pigments. Catalaseand oxidase-positive. The main fatty acids are iso- $15: 0$, iso- $15: 1$, iso- $17: 03-\mathrm{OH}$ and summed feature $3(16: 1 \omega 7 c$ and/or i-15:0 2-OH). The predominant quinone is menaquinone-6. The type species is Sediminibacter furfurosus.

\section{Description of Sediminibacter furfurosus sp. nov.}

Sediminibacter furfurosus (fur.fu.ro'sus. L. masc. adj. furfurosus brownish, because cells in confluent growth have a brownish tinge).

Exhibits the following properties in addition to those described for the genus. Cells are $0.5-0.7 \mu \mathrm{m}$ wide and 
1.0-2.5 $\mu \mathrm{m}$ long. Colonies on marine agar are colourless, but confluent colonies more than 5 days old turn a brownish colour. Growth occurs at temperatures in the range $10-37^{\circ} \mathrm{C}$, with an optimum at $25-30{ }^{\circ} \mathrm{C}$. Growth occurs at $\mathrm{NaCl}$ concentrations of $1-6 \%(\mathrm{w} / \mathrm{v})$, with optimal growth at 3-4\%. Growth does not occur in the absence of $\mathrm{NaCl}$ or at $\mathrm{NaCl}$ concentrations above $6 \%(\mathrm{w} / \mathrm{v})$. Starch, gelatin and DNA are degraded. Chitin, agar, carrageenan, cellulose, CM-cellulose and urea are not degraded. Casein degradation, indole production and $\beta$-glucosidase and $\beta$-galactosidase activities are weakly positive. Acid is not produced from glucose. Nitrate and nitrite are not reduced. $\alpha$-Cyclodextrin, dextrin, glycogen, $N$-acetyl-D-glucosamine, cellobiose, D-fructose, D-galactose, gentiobiose, $\alpha$-D-glucose, $\alpha$-D-lactose, lactulose, maltose, D-mannose, melibiose, methyl $\beta$-D-glucoside, D-psicose, raffinose, D-sorbitol, sucrose, trehalose, turanose, D-galacturonic acid, D-glucosaminic acid, DL-lactic acid, L-alanyl glycine, L-asparagine, L-aspartic acid, L-glutamic acid, glycyl L-aspartic acid, glycyl L-glutamic acid, hydroxy-L-proline, L-ornithine, L-serine, L-threonine, urocanic acid, inosine, uridine, thymidine, glucose 1-phosphate and glucose 6-phosphate are utilized. All other substrates tested are not utilized. The DNA G + C content of the type strain is $39 \mathrm{~mol} \%$.

The type strain, MAOS- $86^{\mathrm{T}}\left(=\mathrm{NBRC} 101622^{\mathrm{T}}=\mathrm{CIP}\right.$ $109285^{\mathrm{T}}$ ) was isolated from a marine-sediment sample collected from the coast at Odawara, Japan.

\section{Description of Gilvibacter gen. nov.}

Gilvibacter (Gil.vi.bac'ter. L. adj. gilvus yellow; N.L. masc. n. bacter rod; N.L. masc. n. Gilvibacter yellow rod).

Gram-negative, non-motile, yellow-coloured, rod-shaped cells. Catalase- and oxidase-positive. The main fatty acids are iso- $15: 0$, iso- $15: 1$, iso- $16: 03-\mathrm{OH}$ and iso- $17: 03-\mathrm{OH}$. The main respiratory quinone is menaquinone- 6 . Flexirubintype pigments are absent. The type species is Gilvibacter sediminis.

\section{Description of Gilvibacter sediminis sp. nov.}

Gilvibacter sediminis (se.di.mi'nis. L. gen. n. sediminis of a sediment).

In addition to the characteristics given in the genus description, the following properties are displayed. Colonies are irregular and are yellow-coloured due to the presence of carotenoid pigments. Cells are $0.5-0.7 \mu \mathrm{m}$ wide and $3.0-$ $5.0 \mu \mathrm{m}$ long. Nitrate is reduced, but nitrite is not reduced. Gelatin, DNA and CM-cellulose are degraded. Chitin, agar, casein, starch, carrageenan, cellulose and urea are not degraded. Acid is not produced from glucose and indole is not produced from tryptophan. Weakly positive for $\beta$-galactosidase and positive for $\beta$-glucosidase. Growth occurs at $15-37^{\circ} \mathrm{C}$ and optimally at $25-30^{\circ} \mathrm{C}$. The optimal $\mathrm{NaCl}$ concentration for growth is $3-4 \%(\mathrm{w} / \mathrm{v})$; growth occurs with $\mathrm{NaCl}$ at concentrations up to $6 \%(\mathrm{w} / \mathrm{v})$. Of the 95 different carbon sources tested on Biolog GN2 microplates, only L-arabinose is utilized. Peptone, sucrose, maltose and D-raffinose are utilized when tested with the protocol of Suzuki et al. (2001). The DNA G + C content of the type strain is $43 \mathrm{~mol} \%$.

The type strain, Mok-1-36 ${ }^{\mathrm{T}} \quad\left(=\mathrm{NBRC} 101626^{\mathrm{T}}=\mathrm{CIP}\right.$ $\left.109286^{\mathrm{T}}\right)$, was isolated from a marine-sediment sample collected from the coast of Okinawa island, Japan.

\section{Acknowledgements}

This work was supported by the New Energy and Industrial Technology Development Organization (NEDO; grant no. 04000182-0).

\section{References}

Abell, G. C. J. \& Bowman, J. P. (2005). Ecological and biogeographic relationships of class Flavobacteria in the Southern Ocean. FEMS Microbiol Ecol 51, 265-277.

Altschul, S. F., Gish, W., Miller, W., Myers, E. W. \& Lipman, D. J. (1990). Basic local alignment search tool. J Mol Biol 215, 403-410.

Bernardet, J.-F., Nakagawa, Y. \& Holmes, B. (2002). Proposed minimal standards for describing new taxa of the family Flavobacteriaceae and emended description of the family. Int J Syst Evol Microbiol 52, 1049-1070.

Cowan, S. T. \& Steel, K. J. (1993). Manual for the Identification of Medical Bacteria, 3rd edn. London: Cambridge University Press.

Fautz, E. \& Reichenbach, H. (1980). A simple test for flexirubin-type pigments. FEMS Microbiol Lett 8, 87-91.

Felsenstein, J. (1985). Confidence limits on phylogenies: an approach using the bootstrap. Evolution 39, 783-791.

Hiraishi, A., Shin, Y. K., Ueda, Y. \& Sugiyama, J. (1994). Automated sequencing of PCR-amplified $16 \mathrm{~S}$ rDNA on 'hydrolink' gels. J Microbiol Methods 30, 145-154.

Mesbah, M., Premachandran, U. \& Whitman, W. B. (1989). Precise measurement of the $\mathrm{G}+\mathrm{C}$ content of deoxyribonucleic acid by high-performance liquid chromatography. Int J Syst Bacteriol 39, 159-167.

Minamisawa, K. (1990). Division of rhizobitoxine-producing and hydrogen-uptake positive strains of Bradyrhizobium japonicum by nifDKE sequence divergence. Plant Cell Physiol 31, 81-89.

Nakagawa, Y. \& Yamasato, K. (1993). Phylogenetic diversity of the genus Cytophaga revealed by $16 \mathrm{~S}$ rRNA sequencing and menaquinone analysis. J Gen Microbiol 139, 1155-1161.

Nedashkovskaya, O. I., Suzuki, M., Vysotskii, M. V. \& Mikhailov, V. V. (2003). Vitellibacter vladivostokensis gen. nov., sp. nov., a new member of the phylum Cytophaga-Flavobacterium-Bacteroides. Int J Syst Evol Microbiol 53, 1281-1286.

Nedashkovskaya, O. I., Kim, S. B., Han, S. K., Rhee, M. S., Lysenko, A. M., Falsen, E., Frolova, G. M., Mikhailov, V. V. \& Bae, S. K. (2004). Ulvibacter litoralis gen. nov., sp. nov., a novel member of the family Flavobacteriaceae isolated from the green alga Ulva fenestrata. Int J Syst Evol Microbiol 54, 119-123.

Perry, L. B. (1973). Gliding motility in some non-spreading flexibacteria. J Appl Bacteriol 36, 227-232.

Reichenbach, H. (1992). Flavobacteriaceae fam. nov. In Validation of the Publication of New Names and New Combinations Previously Effectively Published Outside the IJSB. List No. 41. Int J Syst Bacteriol 42, 327-329. 
Rüger, H.-J. \& Krambeck, H.-J. (1994). Evaluation of the BIOLOG substrate metabolism system for classification of marine bacteria. Syst Appl Microbiol 17, 281-288.

Saitou, N. \& Nei, M. (1987). The neighbor-joining method: a new method for reconstructing phylogenetic trees. Mol Biol Evol 4, 406-425.

Suzuki, M., Nakagawa, Y., Harayama, S. \& Yamamoto, S. (2001). Phylogenetic analysis and taxonomic study of marine Cytophaga-like bacteria: proposal for Tenacibaculum gen. nov. with Tenacibaculum maritimum comb. nov. and Tenacibaculum ovolyticum comb. nov., and description of Tenacibaculum mesophilum sp. nov. and Tenacibaculum amylolyticum sp. nov. Int J Syst Evol Microbiol 51, 1639-1652.

Swofford, D. L. (2000). PAUP*: Phylogenetic analysis using parsimony (*and other methods), version 4. Sunderland, MA: Sinauer Associates.

Thompson, J. D., Gibson, T. J., Plewniak, F., Jeanmougin, F. \& Higgins, D. G. (1997). The CLUSTAL_X windows interface: flexible strategies for multiple sequence alignment aided by quality analysis tools. Nucleic Acids Res 25, 4876-4882. 